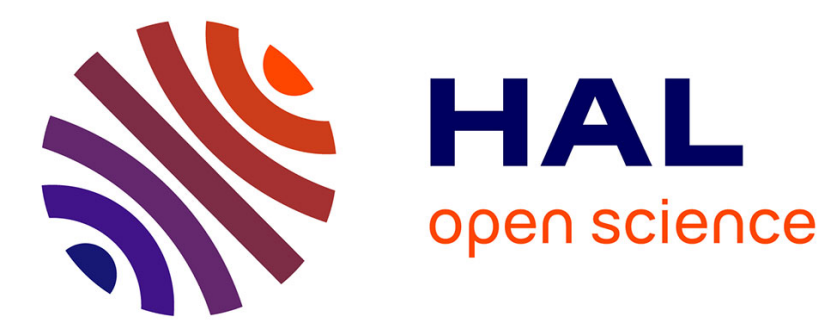

\title{
Nonconceptual representations for action and the limits of intentional control
}

Elisabeth Pacherie

\section{To cite this version:}

Elisabeth Pacherie. Nonconceptual representations for action and the limits of intentional control. Social psychology, 2011, 42 (1), pp.67-73. 10.1027/1864-9335/a000044 . ijn_00778373

\section{HAL Id: ijn_00778373 \\ https://hal.science/ijn_00778373}

Submitted on 19 Jan 2013

HAL is a multi-disciplinary open access archive for the deposit and dissemination of scientific research documents, whether they are published or not. The documents may come from teaching and research institutions in France or abroad, or from public or private research centers.
L'archive ouverte pluridisciplinaire HAL, est destinée au dépôt et à la diffusion de documents scientifiques de niveau recherche, publiés ou non, émanant des établissements d'enseignement et de recherche français ou étrangers, des laboratoires publics ou privés. 
Pacherie, E. (2011). Nonconceptual representations for action and the limits of intentional control. Social Psychology. 42(1): 67-73.

\title{
Nonconceptual representations for action and the limits of intentional control
}

\author{
Elisabeth Pacherie \\ Institut Jean Nicod, Paris \\ EHESS, DEC-ENS, CNRS, Paris, France
}

\begin{abstract}
I argue that to make intentional actions fully intelligible, we need to posit representations of action whose content is nonconceptual. I further argue that an analysis of the properties of these nonconceptual representations and of their relations to action representations at higher levels sheds light on the limits of intentional control. On the one hand, the capacity to form nonconceptual representations of goal-directed movements underwrites the capacity to acquire executable concepts of these movements, thus allowing them to come under intentional control. On the other hand, the degree of autonomy these nonconceptual representations enjoy and the specific temporal constraints stemming from their role in motor control set limits on intentional control over action execution.
\end{abstract}

Keywords: action; motor representation; nonconceptual content; motor control; intentional control. 


\section{Introduction}

This paper aims at (1) providing a defense of the notion of representations with nonconceptual content (henceforth, nonconceptual representations for short) in the domain of action, showing that this notion is both coherent and explanatorily useful, (2) specifying the relations between these representations and higher-level conceptual representations also involved in action control, and (3) assessing their impact, both positive and negative, on intentional action control.

The very idea of intentional control implies that intentions can have a causal impact on action in virtue of their contents. Perhaps the most basic obstacle to the exercise of intentional control lies in the inability to convert intentions into actions. The efficacy of intentions depends on their executability and, I shall argue, their executability ultimately depends on the availability of relevant motor representations. However, it is not sufficient for the exercise of intentional control that relevant motor representations be available, they must also be appropriately harnessed to intentions. Thus, an exploration of nonconceptual representations and their relations to higher-level representation of action is also an exploration of the outer bounds of intentional control over actions.

The notion of nonconceptual content was first explicitly introduced by Gareth Evans (1982). On a standard formulation, a mental state has nonconceptual content if it is possible for a subject to be in that state without possessing any of the concepts a theorist would use in giving a specification of the state's content. This characterization, one should note, is purely negative. Positive characterizations of the notion of nonconceptual content depend on the domains in which it is applied. Since its inception, the notion of nonconceptual concept has been deployed in three main representational domains with different explanatory projects (Bermúdez, 2007; Bermúdez \& Cahen, 2008).

The first, and the one that has most exerted philosophers, is the project of characterizing the content of perceptual experience, clarifying the epistemological relation between perceptual states and belief states, accounting for the phenomenological differences between beliefs and 
perceptions, and explaining the acquisition of observational concepts. The second project is that of characterizing the contents of the representational states attributed to pre-linguistic or non-linguistic creatures in much contemporary developmental and comparative psychology, cognitive ethology and cognitive archeology. Finally, the third project is that of characterizing the content of the subpersonal representational states postulated by the dominant paradigm of cognition as information-processing.

With but a few exceptions (Hurley, 1998), nonconceptual content has played very little role in discussions of the nature and contents of representations of action. As a consequence, attempts to motivate positing nonconceptual content have almost never adduced considerations arising from the study of action. A specific defense of the notion of nonconceptual representations in the domain of action involves showing that this notion does useful explanatory work in that domain and giving a positive account of the nonconceptual content of representations of action.

I will proceed as follows. My first task will be to try and demonstrate the usefulness of nonconceptual representations. In section 2, my argument will be that standard models of action explanation are incomplete, leaving an explanatory gap between the mental antecedent of an action and the specific act it causes and that in order to fill this gap we need to introduce representations of the movements that will implement the intended actions. In section 3, I will further argue that the most basic of these representations cannot be conceptual representations but must be seen as nonconceptual. In section 4, I will offer a positive characterization of these nonconceptual representations of action and highlight their distinctive features. Finally, in section 5, I'll explore in what sense these nonconceptual representations both enable and set limits to intentional control.

\section{The problem of the wrong movement}

I briefly described above a number of explanatory projects where the notion of nonconceptual content has been brought into play. Many of these projects have counterparts in the domain of action. Appeal to nonconceptual representations may be thought necessary to account for the 
distinctive features of the phenomenology of action and to ground action concepts. Insofar as creatures who altogether lack concept-forming abilities or haven't yet acquired relevant concepts appear to engage in forms of intentional action or at least goal-directed behavior, the notion of nonconceptual content may be utilized to account for these abilities. It may also be utilized to characterize the content of the subpersonal representational states implicated in tacit knowledge of the motor rules and biomechanical constraints postulated in theories of motor cognition. Here, I will focus on a particular problem, the problem of the wrong movement, and argue that we need appeal to non-conceptual representations to solve that problem.

In philosophical action theory it is customary to explain actions in terms of the beliefs and desires that motivated the agent to act has she did. Typically, a motivating complex for action $\mathrm{A}$ is thought to include a pro-attitude toward actions with a certain property $\mathrm{P}-$ such as bringing about a certain result or state of affairs, an orienting belief of the agent that she is in circumstances $\mathrm{C}$ and an instrumental belief that action $\mathrm{A}$ in $\mathrm{C}$ has property $\mathrm{P}$. Typically as well, the success of failure of the action is thought to depend on the truth or falsity of the beliefs in the motivating complex.

However, this standard causal model of action explanation is faced with several difficulties. I will here consider only one of them, the problem of the wrong movement, pointed out by Israel, Perry and Tutiya (1993). ${ }^{1}$ The problem is that the failure of an action cannot always be traced back to the falsity of some belief figuring in the motivating complex as it conceived of in the standard model. Israel et al. illustrate this with the following example. Suppose Brutus intends to kill Caesar by stabbing him. His orienting belief that Caesar is to his left and his instrumental belief that stabbing Caesar in the chest would kill him may both be true and yet Brutus may fail to kill Caesar because he makes the wrong movement and misses Caesar completely. In other words, the truth of the beliefs figuring in the motivating complex as it is traditionally conceived does not guarantee that the bodily movement performed by the agent is appropriate. 
Furthermore, his movement could be wrong in two different ways. It could be the case that he simply does not make the movement he was trying to make or it could be that he makes the movement he was trying to make but that that movement is not the right one - in other words, Brutus is wrong to think that that movement would constitute a stabbing of the person to his left. Israel et al.'s conclusion is that something is missing in the traditional account: "Brutus' motivating complex needs to reflect which movement he is trying to make, and what he thinks its effect will be" (1993: 528).

On Israel et al.'s view, for a motivating complex to really explain an action, it must include not just a desire for a certain result, an orienting belief, and an instrumental belief, but also what they call a belief-how. Whereas an instrumental belief is a belief that performing a certain action is a way of achieving a certain result - e.g., stabbing Caesar is a way of killing Caesar -, a belief-how concerns the relations between movements and action - performing movements of a certain kind in certain circumstances constitute a stabbing of Caesar in those circumstances. Moreover, for an agent to have such a belief-how, not just any idea of the type of movement in question will do, the agent must have an executable idea of it. That is, he must know how or think he knows how to perform movements of this type.

In this model the gap between the motivating complex and the act it motivates if filled by a belief-how. Yet, it remains somewhat unclear how exactly Israel et al. conceive of the movement representations involved in beliefs-how. They could have in mind a detailed representation of a very specific bodily movement (or sequence thereof) where this would also require of the agents that they have very detailed beliefs about the circumstances, since exactly what movements should be performed depends on what exactly the circumstances are. Alternatively, they could have in mind a more schematic representation of a type of bodily movement. As Dokic (1999) points out, they are faced with a dilemma. The first option is not very plausible. It requires the agent to form a very detailed representation of the movement before its execution, but this threatens to impose an excessive cognitive burden on the agent, especially if the movement is somewhat complex. On the other hand, if we take the second

\footnotetext{
${ }^{1}$ Other difficulties include the notorious problem of causal deviance as well as problems posed by the status of
} 
option and let the representation of the movement be schematic, we will not be in a position to account for the specific conditions of success of the action, where this success depends on how well movements are adjusted to circumstances.

Yet, there is one way out of the dilemma. The dilemma depends on the assumption that all the representational work has to be done and be over with before the execution starts. But this assumption is quite implausible. Representations do not just trigger the action; they also guide and control it until its completion. One way to account for the specific conditions of success of an action, while avoiding the problem of cognitive overload, is to consider that the representations that guide and control the movement are not fully specified before its onset but are dynamical and relational and serve to adjust the movement to the changing context in which it unfolds. To put it another way, the degree of specification of the bodily movements depends on the degree of specification of the circumstances. It is implausible to suppose that an agent represents all these circumstances in advance of the action.

Israel's et al. themselves insist that we are attuned to a limited range of environments and that facts that are uniform or stable in those environments (e.g. Earth's gravitational force, the impenetrability of physical bodies, illumination from above in outdoors environments) need not be explicitly represented because they are already reflected in the way agents are built both physically and cognitively. But the point here is that even if we limit ourselves to circumstances that are variable and relevant to the success of the action, we need not explicitly represent them in all their details before starting to act. It is enough that the agent represents the circumstances to the extent that he can discern that they allow for an action that would bring out a certain result to be performed and also discern that executing movements of a certain type would be a mode of accomplishing this action in those circumstances.

Very general and stable circumstances don't have to be explicitly represented at the level of the motivating complex, because they are already reflected in the way we are built. The variable circumstances that have to be represented for an action to be executed divide, I contend, into macro-circumstances, represented in advance of action and at the level of the 
motivating complex and into very specific and transitory micro-circumstances that are represented as the action proceeds.

This distinction allows us to give a better account of the problem of the wrong movement. Recall that this problem is twofold. The agent may be wrong in thinking that performing a movement of a certain type would bring about some intended result or, although he is right in that respect, the movement he performs is not of that type. Israel et al. have a ready explanation for wrong movements of the first category. Here, the agent's belief-how explains why he makes the movement he does and the incorrectness of his belief-how explains why his movement is wrong. But the only thing they can say about the second category of wrong movement is that the belief-how does not cause a movement of the type it represents. On this picture the wrong movement is in no way rationalized; what we have is only the brute fact of a causal failure. But if instead of just considering beliefs-how, we also consider the dynamical representations internal to the execution of the action, failures of the second kind may also be made intelligible. Thus, in order to account for wrong movements in the second category, we need to appeal to a further level of movement representations. Let us call these latter representations motor representations.

\section{Motor representations as nonconceptual representations}

The relation of beliefs-how to motor representations is, I shall contend, analog in several important ways to the relation of perceptual beliefs to perceptual experience, where the content of perceptual beliefs involves observational concepts and an observational concept of $\mathrm{X}$, is partially individuated by its relation to a way of perceptually representing $\mathrm{X}$. As pointed out by Bermúdez (2007), one central argument for the claim that perception has nonconceptual content is the priority argument. The observational concepts we possess are a function of the perceptual discriminations we are capable of making, not the other way round. Therefore, we cannot take observational concepts to be explanatorily basic. If the proposed analogy between action and perception holds, then motor representations have nonconceptual content and the executable concepts of movements that are constituents of the contents beliefs-how are the action-analogs of observational concepts. 
As defined by Tutiya et al., an executable concept of a type of movement is a representation, that could guide the formation of a volition, itself the proximal cause of a corresponding movement. Possession of an executable concept of a type of movement thus implies a capacity to form volitions that cause the production of movements that are instances of that type. Such executable concepts of movements can only be possessed, I will argue, by agents that already have executable nonconceptual representations of movements. The argument here is an instance of the priority argument. It is simply that the executable concepts we possess are a function of the movements we are capable of executing. It is not the case that the movements we are capable of executing depend on the executable concepts we possess (although, as we shall discuss in section 5, it may be the case that the movements we are capable of producing intentionally depend on the executable concepts we possess). But the capacity to execute movements of a certain type requires that the agent already have executable representations of those movements. If circularity or infinite regress are to be avoided, these executable representations cannot in turn involve executable concepts of movement types.

But why insist that the executable concepts an agent can possess depend on the movements the agent herself can perform and why insist that performance of these movements involve executive representations? This insistence is motivated by the need to secure the executability of these concepts. We can indeed acquire concepts of types of movement by simply watching someone else perform movements of that type. But these will typically be observational rather than executable concepts of movements. If I am a spectator at an ice-skating competition, I may indeed form observational concepts of the movements performed by the skaters based on my perception of them. But the concepts in question may well fail to be executable concepts. That I formed a concept of a certain movement by watching an ice-skater perform a tripleaxel in no way guarantees that I will be able to perform this movement myself. Similarly, I will not acquire an executable concept of a movement type by simply observing some movement my body makes, if the movement in question is simply a bodily happening (a feverish shaking of my body, say) rather than a movement I can effect. Thus, a genuinely 
executable concept must hook up to movements that are already under the control of motor representations. An executable concept is a concept of movements already executable by the agent, not a concept of movements that in some mysterious way would make them executable.

Let me take stock. I have argued that the executable concepts an agent can possess are a function of the movements he is capable of executing and that executable movements are movements that are under the control of motor representations. On pain or circularity or regress, these motor representations cannot themselves already involve concepts of movements and thus must have nonconceptual content. Nor should their nonconceptual content be identified with nonconceptual perceptual content, for nonconceptual perceptual representations of movement do not constitute a sufficient basis for the formation of executable concepts of movements.

\section{Content and directionality of motor representations}

What exactly are the contents of nonconceptual motor representations, how do they guide and control movements and what is their directionality? For answers to these questions we must turn to the cognitive neuroscience of action. I will not attempt to review the already considerable and fast growing empirical literature on motor representations. For my present purpose, a brief description of the main characteristics of these representations will suffice.

It is now generally agreed that there exist two visual systems, dedicated respectively to vision for action and for the identification and recognition of objects and scenes (Milner \& Goodale, 1995, Jacob \& Jeannerod, 2003). The vision for action system extracts from visual stimuli information about the properties of objects and situations that is relevant to action, and uses this information to build motor representations used in effecting rapid visuo-motor transformations. The motor representations produced by this system have three important characteristics. First, the attributes of objects and situations are represented in a format useful for the immediate selection of appropriate motor patterns. For instance, if one wants to grab an object, its spatial position will be represented in terms of the movements needed to reach 
for it and its shape and size in terms of the type of hand grip it affords. Second, these representations of the movements to be effected reflect an implicit knowledge of the biomechanical constraints and the kinematic and dynamic rules governing the motor system. Thus, for instance, the movements of the effectors will be programmed so as to avoid awkward or uncomfortable hand positions and to minimize the time spent in extreme joint angles. Third, a motor representation normally codes for transitive movements, where the goal of the action determines the global organization of the motor sequence. For instance, the type of grip chosen for a given object is a function not just of its intrinsic characteristics (its shape and size) but also of the subsequent use one wants to make of it. The same cup will be seized in different ways depending on whether one wants to carry it to one's lips or to put it upside down. As this brief characterization makes clear, what motor representations represent are neither the current state of the agent's body nor the current state of the environment, nor just the current relation between body and environment. Rather, what they represent are the ways (the motor patterns) through which the current relation can be transformed into a desired relation (goal state) ${ }^{2}$

Another important aspect of motor representations is their dynamical character. Motor representations guide and control movements as long as they unfold. In order to guide movements, they must anticipate their effects. In order to control them, they must allow for adjustments during execution. Feedback - that is, visual, kinesthetic, or proprioceptive reafferences -- will be needed to make adjustments. For instance, in order to lift an object, the appropriate grip force and load force must be computed using information about size, texture, compliance, hardness and weight. But from vision alone one can only get rough estimates of some of these properties, sensory reafferences in other modalities resulting from one's attempt at lifting the object will allow the motor system to make adjustments to the grip force and load force initially programmed. The contents of motor representations are thus dynamical in the sense both that they get more determinate over time and that they are themselves

\footnotetext{
${ }^{2}$ For in-depth discussions of the properties of motor representations, see Jeannerod $(1997,2006)$
} 
responsible for making available the information needed for their further specification - this information is made available by the reafferences they yield.

The relational and dynamical character of motor representations also heralds their distinctive directionality. Motor representations code simultaneously for things that are coded separately at the (conceptual) level of the antecedent motivating complex. The antecedent motivating complex for an action includes both conative and doxastic elements, namely, on the conative side, a desire that a certain result $R$ obtain, and on the doxastic side, orienting beliefs, instrumental beliefs and beliefs-how. Situation, goal and means are thus represented separately at that level. There is no such dissociation at the level of motor representations. The situation is coded in terms of a goal it affords and the goal itself is coded in terms of the means - i.e. the motor commands - towards its achievement. Proto-doxastic and protoconative elements are thus inextricably intertwined. One consequence of this intertwining is that the classical distinction between states with a mind-to-word direction of fit and states with a world-to-mind direction of fit $^{3}$ gets blurred at the level of motor representations. Motor representations are what Millikan (1995) calls pushmi-pullyu representations, having at once a mind-to-world and a world-to-mind direction of fit. A motor representation represents a situation as affording a certain goal (mind-to-world direction of fit), and it does so by representing the motoric means by which the goal is to be achieved (world-to-mind direction of fit).

\section{Nonconceptual motor representations and intentional control}

To a first approximation, we have intentional control over our actions to the extent that we are able to form and execute intentions geared towards the satisfaction of consciously endorsed goals. There are various obstacles to the exercise of intentional control. We may be aware of well-entrenched action tendencies that go against what we are trying to achieve and yet we

\footnotetext{
3 The concept of direction of fit, introduced by Searle, is used in philosophy of mind to distinguish between two types of intentional mental states. States with a mind-to-world direction of fit (e.g., beliefs, perceptions,
} 
may fail to inhibit the habitual responses they yield. Worse perhaps, we may be completely unaware of factors that influence our decisions and actions and as a result unable to resist their influence, being thus left with only the illusion of intentional control. However, the most basic obstacle to the exercise of intentional control lies not so much in the inability to resist countervailing influences than in the inability to convert intentions into actions, even absent such countervailing influences.

As the problem of the wrong movement shows, one's intention to perform a certain action A with a view to bring about result $\mathrm{R}$ will only succeed if one knows how to execute movements appropriate to the performance of A. Hence the need to introduce beliefs-how in motivating complexes if they are to really explain actions. To have beliefs-how, an agent must have executable concepts of types of movement and such executable concepts, or so I argued in section 3, must themselves be grounded on motor representations we antecedently possess; i.e. on executable nonconceptual representations of movements.

Thus, the efficacy of intentions depends on their executability and their executability ultimately depends on the availability of appropriate motor representations. The availability of motor representations is not, however, a sufficient condition for the causal efficacy of intentions, only an enabling condition. The mediation of beliefs-how is needed to place motor representations under intentional control. Ideomotor apraxia provides a dramatic illustration of this point. People suffering from ideomotor apraxia know what one is supposed to do to perform a certain action, they know, say, that waving goodbye involves moving one's arm and hand in a certain way and they can recognize that someone is weaving goodbye when seeing them. What they can't do is consciously and voluntarily initiate and perform the action in the absence of environmental triggers (Wheaton \& Hallett, 2007). In other words, they have intact motor representations of the relevant movements, they have concepts of the types of movements associated with an action enabling them to describe or recognize them, but what they seem to have lost are executable concepts of the types of movements needed to a world-to-mind direction of fit (desires, intentions) are satisfied if the world changes to match their content. 
perform the action. Lacking those executable concepts, they are unable to voluntarily initiate actions.

The alignment of intentions, beliefs-how and motor representations is made possible by the teleological structure they share. ${ }^{4}$ As I tried to show in section 4 , the movements motor representations represent and bring about are relationally characterized movements movements related to a certain goal. Thus, intentions, beliefs-how and motor representations all represent relations between means and goals, although at different levels of grain. An intention represent an action of a certain type as a way of bringing about a certain result $\mathrm{R}$ in circumstances $\mathrm{C}$, a belief-how represents the execution of movements of a certain type as a mode of bringing about $\mathrm{R}$ in circumstances $\mathrm{C}^{\prime}$ and thus accomplishing the action and motor representations represent motor commands as a way of executing these movements and bringing about $\mathrm{R}$ in circumstances C", where circumstances C' and C" are specifications of circumstances $\mathrm{C}$ that impose further constraints on action execution. Or, to put it the other way around, beliefs-how are representations of means to goals that abstract away from certain specifics of the circumstances of action and intentions are representations that abstract further away from these specifics.

The availability of motor representations is an enabling condition of the efficacy of intentions. Through the mediation of beliefs-how these motor representations can come under intentional control. Motor representations do not depend on beliefs-how or intentions for their existence, however. To the extent that they retain some autonomy, they can eschew intentional control. There are at least two ways in which they can do so. One is simply that motor representations can be directly triggered by environmental stimuli or affordances and thus initiate actions. In such cases, intentional control is not in principle impossible. One can still veto or inhibit the execution of the action provided one notices what is going on. Yet, the vigilance required to do so rapidly puts a strain on attentional resources. Thus, when attentional resources are depleted or allocated elsewhere, environmentally triggered motor representations and ensuing actions can easily bypass intentional control. 
A second, more principled, way in which motor representations resist intentional control relates to their limited cognitive penetrability and thus their partial autonomy. Some aspects of the operation of the motor system that generate motor representations appear to be consciously accessible. They are reflected in conscious motor imagery and provide the anchoring ground for executable concepts of types of movement. Yet, we are not aware of the way immediate sensory information is used for the fine-tuning of motor commands and thus of their precise details (Fourneret and Jeannerod, 1998). For instance, several pointing experiments (Goodale et al., 1986; Castiello et al., 1991) have shown that in a task where subjects have to point with their finger a target, they can do so accurately even on trials where the target is suddenly displaced by several degrees and they have to adjust their trajectories. Moreover, they can do so while remaining completely unaware both of the displacement of the target and of their own corrections. What I called in section 4 the dynamical character of motor representations - their constant updating in response to sensory reafferences - is needed to insure smooth online corrections and adjustments of movements. Motor control, in other words, is subject to very tight temporal constraints. Intentional action control, on the other hand, is a form of conscious control based on consciously available information and conscious processing is comparatively slow. There is thus at least a partial incompatibility between the temporal constraints motor control must satisfy to be efficient and the temporal constraints on conscious processes. To that extent, the demands of motor control are incompatible with the demands of intentional control.

To recap, our discussion of the contents and teleological structure of nonconceptual motor representations allowed us to explore some of the limits of intentional control. Motor representations are the proximal causes of goal-directed movements. On the one hand, the capacity to form motor representations underwrites the capacity to acquire the executable concepts of movements and thus to acquire beliefs-how. Beliefs-how in turn make it possible to harness motor representations onto intentions, thus permitting intentional action control. On the other hand, motor representations retain some autonomy. They can be formed

\footnotetext{
${ }^{4}$ For further discussion, see Pacherie $(2006,2008)$.
} 
independently of intentions and as a result may bypass intentional action control. Their role in motor control makes also them subject to specific temporal constraints, at least partially incompatible with the temporal constraints of intentional action control. Thus, as well as enabling, via beliefs-how, intentional control over action execution, motor representations also set limits on intentional control..$^{5}$

\section{References}

Bermúdez, J. L. (2007). What is at stake in the debate on nonconceptual content? Philosophical Perspectives, 21: 55-72.

Bermúdez, J. L., \& Cahen, A. (2008). Nonconceptual Mental Content. The Stanford Encyclopedia of Philosophy, Edward N. Zalta (ed.), <http://plato.stanford.edu/entries/contentnonconceptual/>.

Castiello, U., Paulignan, Y., \& Jeannerod, M. (1991). Temporal dissociation of motor responses and subjective awareness. A study in normal subjects. Brain, 114: 2639-2655.

Dokic, J. (1999). L'Action Située et le Principe de Ramsey. In M. de Fornel and L. Quéré (Eds.), La Logique des Situations. Nouveaux Regards sur l'Écologie des Activités Sociales, Raisons Pratiques 10 (pp. 131-155). Paris: Editions de l'EHESS.

Evans, G. (1982). The Varieties of Reference. Oxford: Clarendon Press.

Goodale, M.A., Pélisson, D., \& Prablanc, C. (1986). Large adjustments in visually guided reaching do not depend on vision of the hand or perception of target displacement. Nature, 320: $748-750$.

Hurley, S. (1998). Consciousness in Action. Cambridge MA: MIT Press.

Israel, D., Perry, J., \& Tutiya, S. (1993). Executions, Motivations and Accomplishments. The Philosophical Review, 102: 515-540.

Jacob, P., \& Jeannerod, M. (2003). Ways of Seeing, the Scope and Limits of Visual Cognition. Oxford: Oxford University Press.

Jeannerod, M. (1997). The Cognitive Neuroscience of Action. Oxford: Blackwell.

Jeannerod, M. (2006). Motor cognition. Oxford: Oxford University Press.

Millikan, R. G. (1995). Pushmi-pullyu representations. Philosophical Perspectives, IX: 185200 .

Milner, A. D., \& Goodale, M. A. (1995). The Visual Brain in Action. Oxford: Oxford University Press.

\footnotetext{
5 Thanks to Michael Schmitz and Julien Deonna for helpful comments and suggestions on a previous draft of this paper.
} 
Pacherie, E. (2006). Towards a dynamic theory of intentions. In S. Pockett, W.P. Banks \& S. Gallagher (Eds.), Does Consciousness Cause Behavior? An Investigation of the Nature of Volition (pp. 145-167). Cambridge, MA: MIT Press.

Pacherie, E. (2008). The phenomenology of action: A conceptual framework. Cognition, 107,1: 179-217.

Wheaton, L. A., \& Hallett M. (2007). Ideomotor apraxia: a review. Journal of Neurological Sciences, 260, 1: 1-10. 